\title{
Study of structural and optical properties of cupric oxide nanoparticles
}

\author{
N. R. Dhineshbabu ${ }^{1,2} \cdot$ V. Rajendran ${ }^{1} \cdot$ N. Nithyavathy $^{1} \cdot$ R. Vetumperumal $^{3}$
}

Received: 10 August 2015/ Accepted: 3 September 2015/Published online: 13 September 2015

(C) The Author(s) 2015. This article is published with open access at Springerlink.com

\begin{abstract}
In this study, cupric oxide (CuO) nanoparticles were synthesized via sonochemical method. The samples were characterized by X-ray diffraction, Fourier transform infrared spectroscopy, scanning electron microscope, and transmission electron microscopy. The spherical $\mathrm{CuO}$ nanoparticles were dispersed in sodium hexametaphosphate under sonication $(25 \mathrm{kHz})$ to analyze the particle size distribution and UV absorption spectra. Using these absorption spectra, we further examined the $\mathrm{CuO}$ nanoparticle to explore the possibility of using them as a material for applications such as solar cell and textile production.
\end{abstract}

Keywords Cupric oxide $\cdot$ Sonochemical method

\section{Introduction}

Nanocrystalline semiconductor particles have drawn considerable interest in recent years due to their interactive properties such as large surface-to-volume ratio and distinctive electronic and optical properties as compared to bulk materials (Huang et al. 2010; Son et al. 2009; Xu

V. Rajendran

veerajendran@gmail.com

1 Centre for Nano Science and Technology, K.S. Rangasamy College of Technology, Tiruchengode, Tamil Nadu 637 215, India

2 Present Address: Department of Electronics and Communication Engineering, V.V. College of Engineering, V.V. Nagar, Tisaiyanvilai, Tamil Nadu 627 657, India

3 Department of Physics, V.V. College of Engineering, V.V. Nagar, Tisaiyanvilai, Tamil Nadu 627 657, India et al. 2007; Lim et al. 2012; Qi et al. 2007; Kidowaki et al. 2012). Cupric oxide (CuO) is a transition metal oxide. It has a monoclinic structure and a narrow bandgap of $1.2 \mathrm{eV}$ (indirect) with p-type semiconductor material. It is also an attractive candidate for light-harvesting applications due to its band gap energy of $1.4 \mathrm{eV}$ (Son et al. 2009; Xu et al. 2007; Lim et al. 2012). CuO compounds are technologically well-known materials that have their applications in areas (Qi et al. 2007) such as solar energy materials, electronic materials, gas sensor, magnetic media, optical devices, batteries and catalyst (Kidowaki et al. 2012; Lang et al. 2006; Teng et al. 2008; Stewart et al. 2004; Wang et al. 2007; Morales et al. 2005), and constructing junction devices such as p-n diode (Muhibbullah et al. 2003), as well as for photoconductive, photothermal, and photoelectrochemical applications (Chiang et al. 2012).

Attempts are made to prepare $\mathrm{CuO}$ nanoparticles using different methods such as spray pyrolysis (Chiang et al. 2012), electrochemical techniques (Chen et al. 2009), hydrothermal treatments (McAuleya et al. 2008), sonochemical method (Gandhi et al. 2010), and wet chemical methods (Mahapatra et al. 2008) with different morphologies. Among these methods, sonochemical preparation method is used to break the chemical bond of the solution compound. In general, formation, development, and implosive collapse of microcavities are the three steps involved in the production of nanoparticles through sonochemical method (Gandhi et al. 2010). Most inorganic materials such as $\mathrm{Al}_{2} \mathrm{O}_{3}, \mathrm{ZnO}, \mathrm{MnO}_{2}, \mathrm{SnO}_{2}, \mathrm{Y}_{2} \mathrm{O}_{3}$, and clay particles may be more dispersed in sodium hexametaphosphate. Sodium polyphosphate (Calgon) is also a suitable dispersing agent (Greenwood 2003). These are the solvents used to readily dissolve in water and they are normally added at approximately $1 \mathrm{wt} \%$. 
The optical behavior of $\mathrm{CuO}$ nanomaterials is mainly assessed through UV-vis and photoluminescence techniques to explore the electronic transitions in semiconductors including band-edge or near-band-edge transitions. Only a few works based on UV-vis analysis are available on the absorption and band gap studies of $\mathrm{CuO}$ nanoparticles (Cho 2013; Lin et al. 2004; Kaur et al. 2006; Tauc et al. 1966). However, optical properties of $\mathrm{CuO}$ nanoparticles are not revealed extensively.

In this article, using a simple and low-cost approach, $\mathrm{CuO}$ nanoparticles were synthesized using sonochemical method and their optical properties were investigated using different characterization techniques.

\section{Experimental}

\section{Materials}

Analytic grade (AR) chemicals namely copper (II) nitrate $\left[\mathrm{Cu}\left(\mathrm{NO}_{3}\right)_{2}\right]$, sodium hydroxide $(\mathrm{NaOH})$, and sodium hexametaphosphate $\left[\mathrm{Na}\left(\mathrm{PO}_{3}\right)_{6}\right]$ obtained from Merck, and deionized water, obtained in our laboratory, were used without any further purification.

\section{Preparation of copper oxide nanoparticles}

In a typical procedure, $50 \mathrm{ml} \mathrm{NaOH}$ solution was dropwise added into $100 \mathrm{ml}$ aqueous $\mathrm{Cu}\left(\mathrm{NO}_{3}\right)_{2} \cdot 2 \mathrm{H}_{2} \mathrm{O}$ solution under sonication process. Meantime, the mixed solution was kept under sonication at a constant interval of $60 \mathrm{~s}$ and frequency of $25 \mathrm{kHz}$ for $60 \mathrm{~min}$ and $\mathrm{pH}$ was maintained at 12. The $\mathrm{Cu}\left(\mathrm{OH}_{2}\right)$ solution thus formed was blackish brown. The precipitate was centrifuged at room temperature at $10,500 \mathrm{rpm}$ and then washed with deionized water several times. Finally, the obtained solution was washed with ethanol to remove ionic impurities and then annealed at $673 \mathrm{~K}$ under vacuum for $4 \mathrm{~h}$. Finally, black $\mathrm{CuO}$ nanoparticles were obtained.

\section{Characterization}

The phase identification was carried out using powder X-ray diffraction (XRD; X'Pert PRO PW-1830; Philips, Germany). The functional group present in the sample was recorded using Fourier transform infrared spectroscopy (FTIR; Spectrum 100; PerkinElmer). The microscopical analysis of the samples was carried out by a scanning electron microscope (SEM; JSM-200; JEOL, USA) equipped with energy-dispersive spectroscopy (EDS), and the powder sample was mixed with ethanol to analyze the sample through transmission electron microscopy (TEM;
JEM-2100; JEOL) along with selected area electron diffraction (SAED) pattern. The $\mathrm{CuO}$ nanoparticles were dispersed in $\left(\mathrm{NaPO}_{3}\right)_{6}$ solution at a ratio of 1:100 and then kept under ultrasonic irradiation $(25 \mathrm{kHz})$ to obtain a homogeneous mixture solution, which was used to analyze particle size distribution by dynamic light scattering technique using a particle size analyzer (PSA; Nanophox, Germany) and optical properties were determined by recording the absorption spectra using a UV spectrometer (Lamda 20; PerkinElmer).

The optical band gap $\left(E_{\mathrm{g}}\right)$ was obtained from the absorption coefficient $(\alpha)$, which was calculated from the transmittance spectra of $\mathrm{CuO}$ nanoparticles. The value of $\alpha$ is given as follows (Khalil et al. 2011; Sumangala et al.

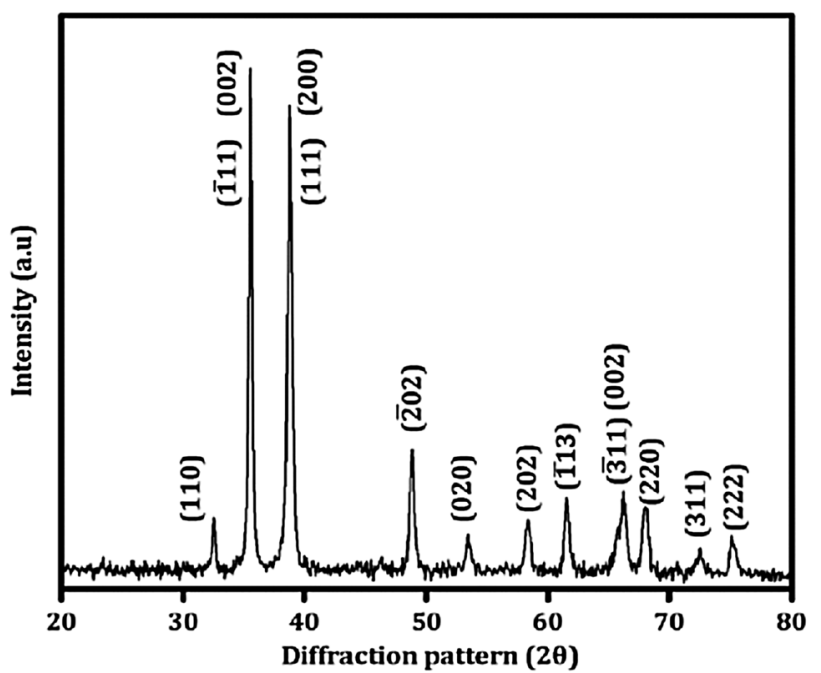

(a) XRD pattern

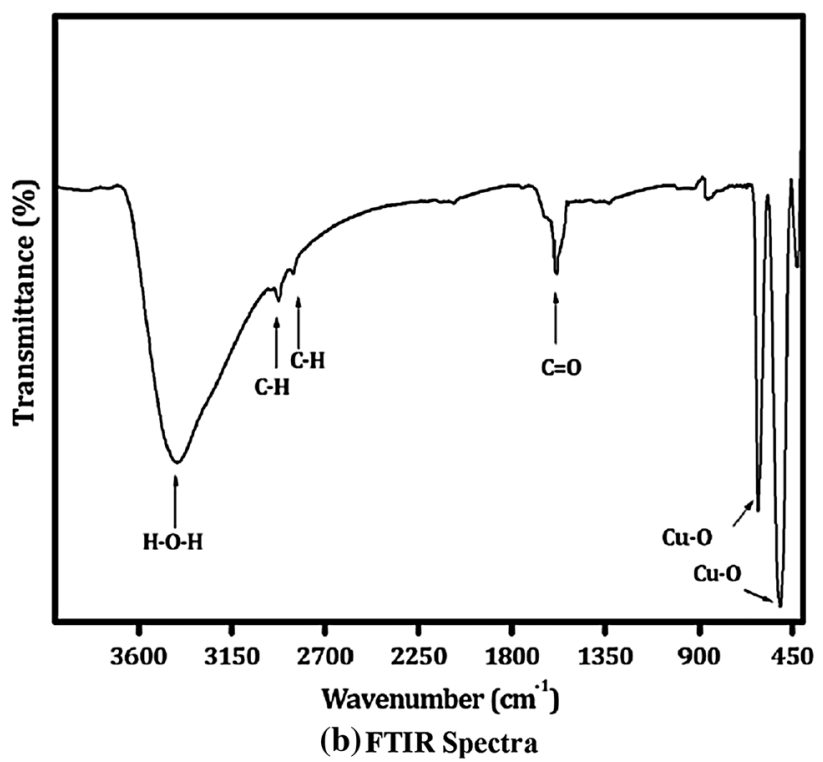

Fig. 1 Characterisation of $\mathrm{CuO}$ nanoparticles a XRD Pattern and b FTIR Spectra 


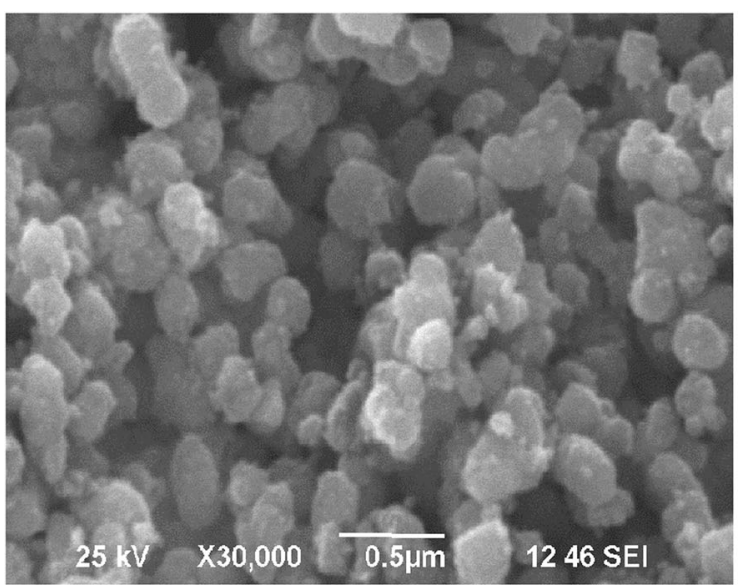

(a) SEM image

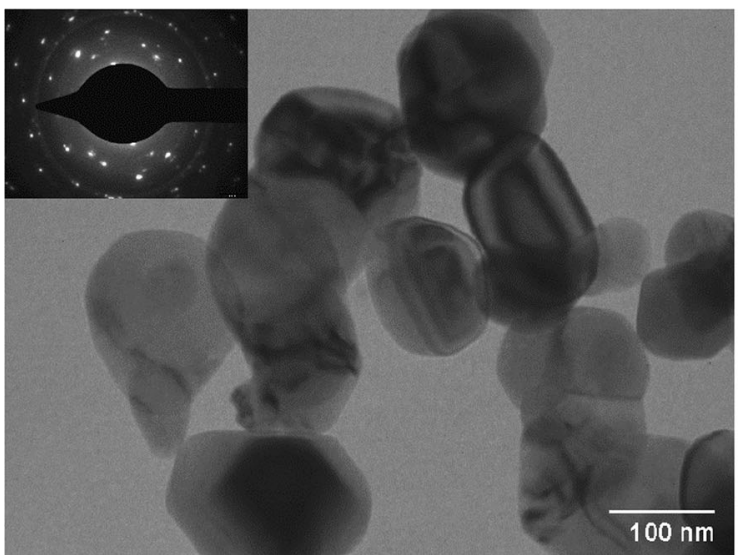

(c) TEM image

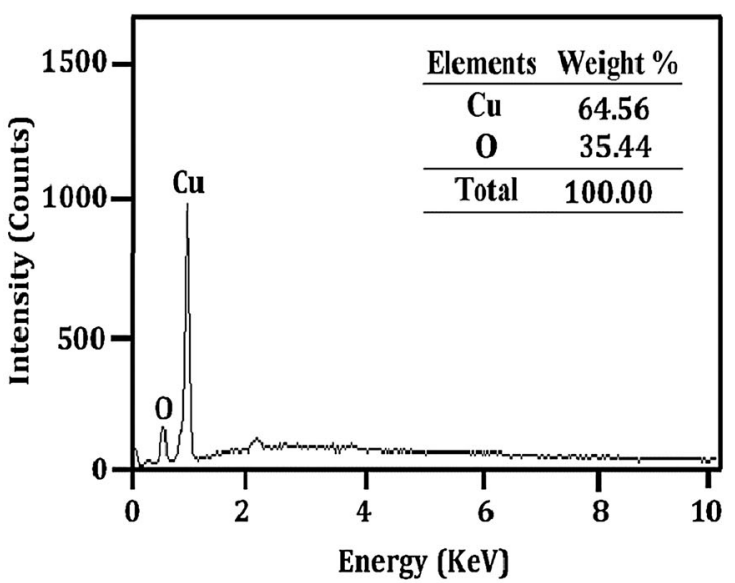

(b) EDS pattern

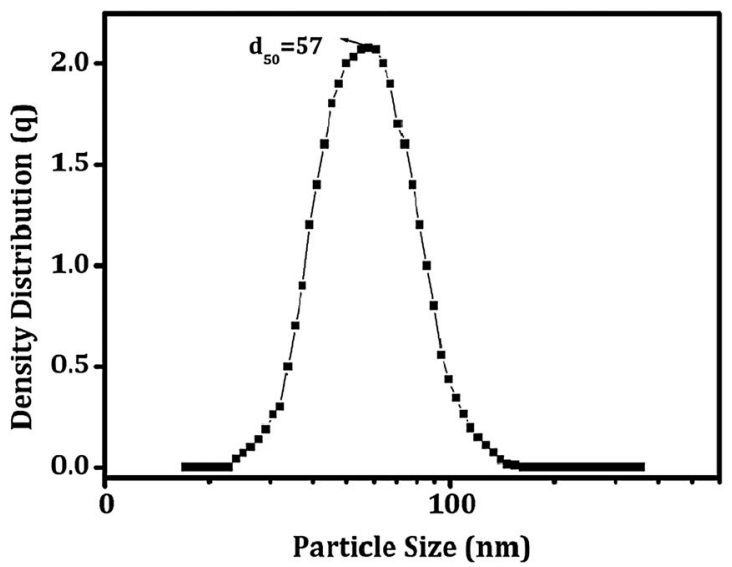

(d) Particle size Distribution

Fig. 2 Characterisation of CuO nanoparticles a SEM image, b EDS pattern, c TEM image and d particle size distribution

2005; Mishra and Mishra 2009; Hamad et al. 2014; Growth 2011):

$\alpha=\frac{1}{d} \ln (1 / T)$

where $d$ is the film thickness, $T$ the transmittance, and $\alpha$ the absorption edge. $\mathrm{CuO}$ is a wide band gap semiconductor material with direct band gap. The optical band gap $\left(E_{\mathrm{g}}\right)$ is given by

$(\alpha h v)^{2}=A\left(h v-E_{g}\right)$

where $\alpha$ is the absorption edge and $h v$ the photon energy. The refractive index $(n)$ and extinction coefficient $(k)$ of $\mathrm{CuO}$ nanoparticles were calculated from the following expressions (Sumangala et al. 2005):

$n=\left(\frac{1+R}{1-R}\right)+\sqrt{\left(\frac{4 R}{(1-R)^{2}}-k^{2}\right)}$

$k=\frac{\alpha \lambda}{4 \pi}$ where $R$ is reflectance, $\lambda$ the wavelength, and $k$ the extinction coefficient.

The Urbach tail of the particles can be determined from the following relation (Growth 2011):

$\alpha=\alpha_{0} \exp \left(\frac{h v}{E_{U}}\right)$

where $\alpha$ is absorption edge, $\alpha_{0}$ a constant, $h v$ the photon energy, and $E_{\mathrm{U}}$ the Urbach energy.

\section{Results and discussion}

\section{Analysis of structural and functional properties}

The crystal phase of $\mathrm{CuO}$ nanoparticles is consistent with JCPDS card no 05-0661 of all diffraction peaks, as shown in Fig. 1a. The sharp observed planes (110), (-111), (111), (202), (020), (220), (-113), and (022) show the monoclinic phase of $\mathrm{CuO}$ nanoparticles. Further, it is evident that there 
are no peaks corresponding to $\mathrm{Cu}_{2} \mathrm{O}$ or $\mathrm{Cu}(\mathrm{OH})_{2}$ phases. The absence of impurities is also reflected from the XRD pattern. The average crystallite size of the $\mathrm{CuO}$ nanoparticles obtained from full-width at half maximum of the diffraction peak is $21 \mathrm{~nm}$.

Figure $1 \mathrm{~b}$ shows the functional property of FTIR spectra. The obtained spectra show an absorbed band of approximately $640 \mathrm{~cm}^{-1}$, which shows the characteristic band of monoclinic phase of pure $\mathrm{CuO}$ similar to that obtained in an earlier report (Gandhi et al. 2010). The bands obtained at 1585 and $1644 \mathrm{~cm}^{-1}$ show the carbonyl $\mathrm{C}=\mathrm{O}$ stretching bonds. Similarly, the $\mathrm{C}-\mathrm{H}$ stretching bonds occur in the region of $3300-2800 \mathrm{~cm}^{-1}$ (Xu et al. 2007). Moreover, the broad band centered at 3413 and $3392 \mathrm{~cm}^{-1}$ is attributed to the stretching and bending vibrations of absorbed water and surface hydroxyls (Gandhi et al. 2010).

Figure 2 shows the SEM and TEM images of the sample. Figure 2a shows the SEM image of $\mathrm{CuO}$ nanoparticles, which consists entirely of flake-like morphology. The fine nanoparticles aggregate due to their high surface energy. EDS analysis of the flake-like $\mathrm{CuO}$ architecture suggests that the sample contains only the identified elements of $\mathrm{Cu}$ and $\mathrm{O}$ with the atomic and weight percentages as shown in the inset of Fig. 2b. It also confirms that the grown nanoparticles are composed of $\mathrm{CuO}$ without any impurities. TEM image suggests that $\mathrm{CuO}$ nanoparticles show relatively uniform diameter in the range of $30-60 \mathrm{~nm}$ (Fig. 2c). SAED pattern shows that the $\mathrm{CuO}$ nanoparticles comprise small nanocrystalline structures with different orientation of the single crystal diffraction pattern. Therefore, the $\mathrm{CuO}$ nanoparticles are crystalline in nature, which closely matches with the XRD pattern. The distribution of $\mathrm{CuO}$ nanoparticles is in the range between 35 and $125 \mathrm{~nm}$. However, the average distribution $\left(\mathrm{d}_{50}\right)$ of the nanoparticles is $57 \mathrm{~nm}$ (Fig. 2d).

\section{Analysis of optical properties}

The absorption edge is found so that the type of transition and bandgap value can be determined (Essic and Mather 1993). The absorption spectra were used to study the energy band and the type of electronic transitions. Absorption spectra of $\mathrm{CuO}$ nanoparticles are shown in Fig. 3a, which show a strong fundamental absorption edge

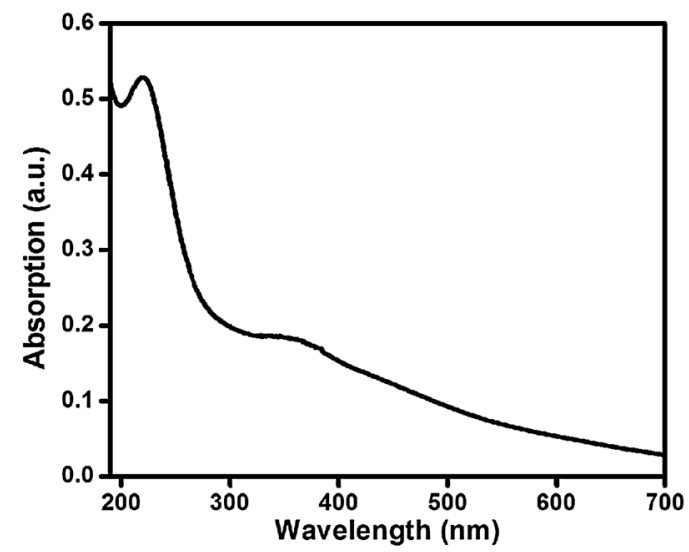

(a) UV absorption

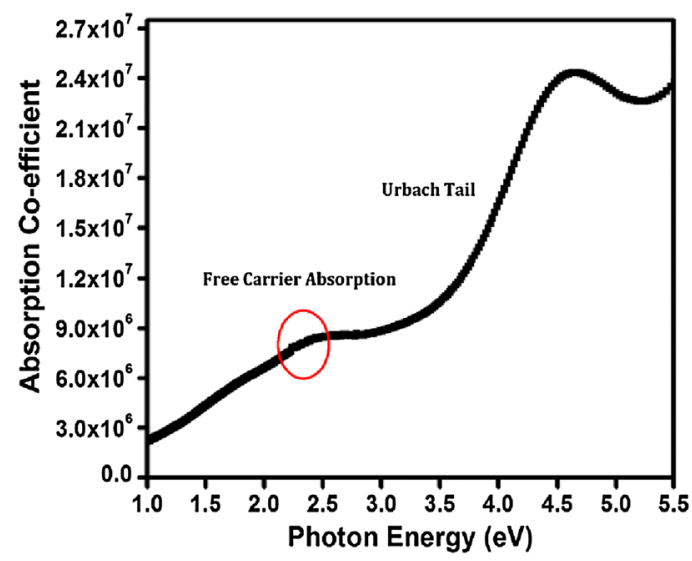

(c) Absorption co-efficient

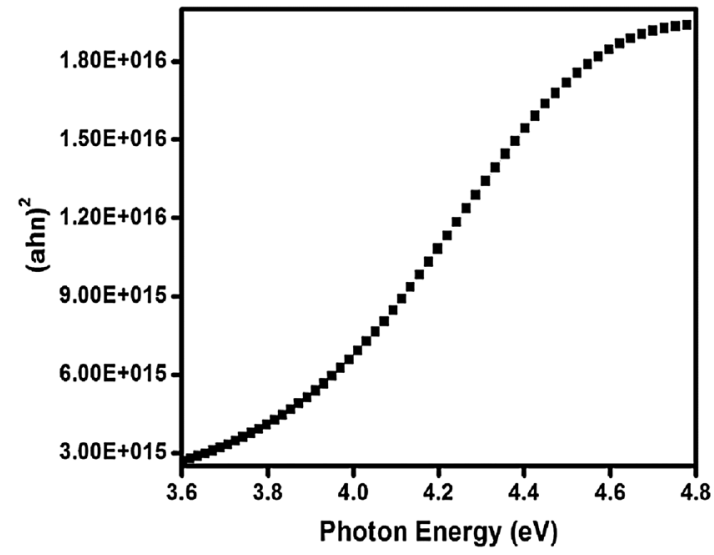

(b) Band gap

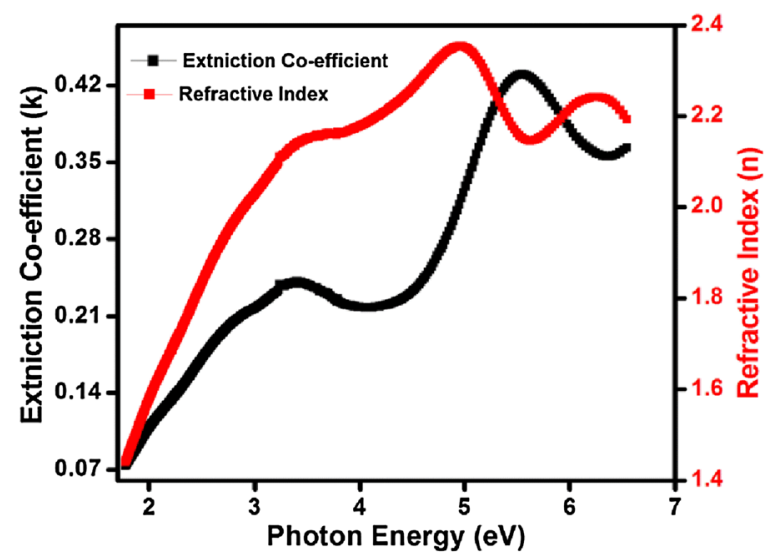

(d) k \& n Values

Fig. 3 Optical properties of $\mathrm{CuO}$ nanoparticles a UV absorption, b band gap, c absorption coefficient and $\mathbf{d} k \& n$ values 
approximately $219 \mathrm{~nm}$ due to direct transition of electrons. Optical absorption shows that the direct band gap compared to indirect band gap permits us to determine the crystallinity of a material. The functional relationship between $\alpha h \gamma$ and photon energy for $\mathrm{CuO}$ nanoparticles is presented in Fig. 3b. The $E_{\mathrm{g}}$ value can be obtained by extrapolating the linear portion to the photon energy axis. If the direct band gap is higher than the indirect band gap, the materials will be crystalline (Radhakrishnan and Beena 2014). The calculated direct band gap value was $3.85 \mathrm{eV}$, which was higher than the bulk band gap value $(3.5 \mathrm{eV})$. Here, only direct transition-related absorption was observed, and there was no indirect transition absorption peak (Fig. 3b). The observed increasing band gap could be ascribed to the presence of intragap states and quantum confinement effect.

The variation of absorption coefficient of $\mathrm{CuO}$ nanoparticles as a function of photon energy is shown in Fig. 3c. The figure clearly shows that the absorption coefficient tends to decrease exponentially as the wavelength increases. This behavior is typical for many semiconductors and could be due to a variety of reasons, such as internal electric fields within the crystal, deformation of lattice due to strain caused by imperfection, and inelastic scattering of charge carriers by phonons (Moss et al. 1973; Honsi et al. 2006; Almqvist 1996). The highest absorption coefficient is observed in the UV region and is in the order of $10^{6}-10^{7}$ from UV to visible region. Elongation of band gap in the form of band tail and absorption due to free carriers are observed from the absorption coefficient.

The $k$ and $n$ values against photon energy plot of $\mathrm{CuO}$ nanoparticles are shown in Fig. 3d. From the image, the refractive index of $\mathrm{CuO}$ nanoparticles is found to increase with an increase in photon energy, whereas it is found to have lesser value than that for the bulk $\mathrm{CuO}(n=2.6)$. For instance at band gap region, the refractive index values range from 2.1 to 2.37. In general, refractive index of the semiconductor is a measure of its transparency to incident spectral radiation. The assessment of the refractive index of the optical material is notably important for applications in integrated optic devices (Xue et al. 2008). The extinction coefficient of $\mathrm{CuO}$ nanoparticles increases with increase in the photon energy. The observed extinction coefficient values are very low (0.42) in the absorption region, and it specifies the smoothness of the surface and homogeneity of the particles.

Optical conductivity of $\mathrm{CuO}$ nanoparticles with respect to the photon energy is shown in Fig. 4a, which describes the free charges (Madhup et al. 2010; Millis et al. 2005; Lupi et al. 2005). Optical conductivity increases with respect to the photon energy in the UV region and it in turn increases the free carriers. The optical conductivity

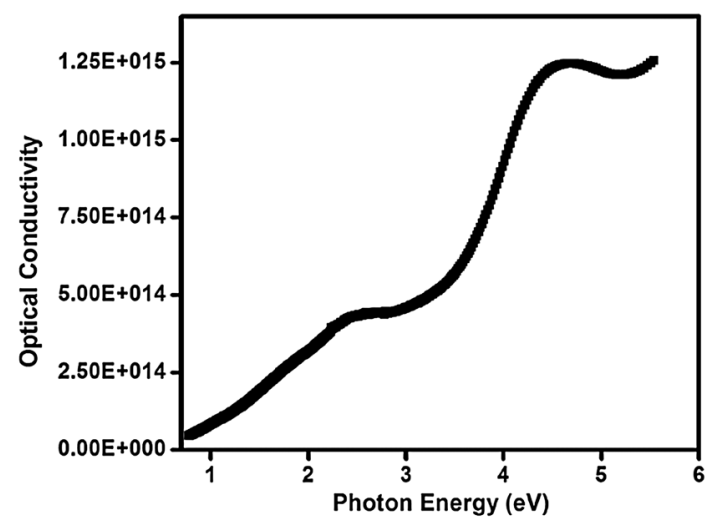

(e) Optical Conductivity

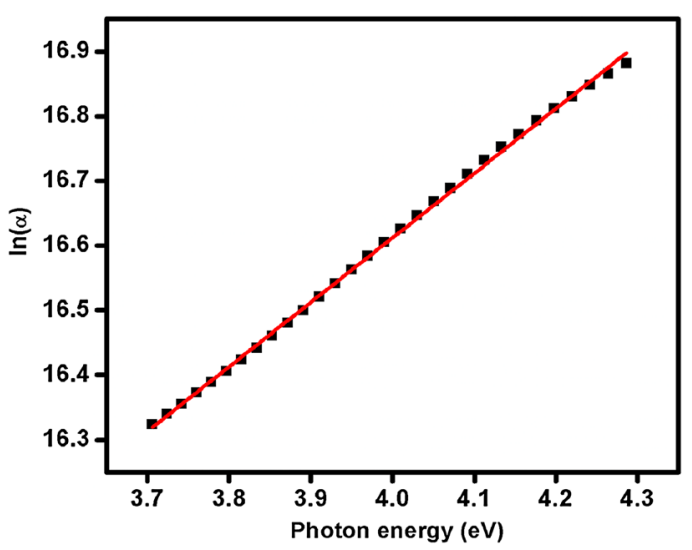

(f) Urbach energy

Fig. 4 Optical properties of $\mathrm{CuO}$ nanoparticles: $e$ optical conductivity and $f$ Urbach energy

dramatically increases in the higher energy region (UV absorption), which indicates the availability of free carriers of photon energy and hence, the maximum of optical conductivity is observed. However, an enormous decrease in the optical conductivity in the visible region is observed due to trapping of free carriers.

The plot of $\ln (\alpha)$ versus photon energy is linear, as shown in Fig. 4b. Urbach energy is obtained from the inverse of the slope (see the figure) and the calculated Urbach energy value of $\mathrm{CuO}$ nanoparticles is found to be $1.01 \mathrm{eV}$, which is higher than that of the other metal oxides. Basically, Urbach energy depends on the static and induced disorder, temperature, strong ionic bonds, and average photon energies (Gandhi et al. 2010). Urbach band tail calculation can be performed to confirm the change in band gap energy and the interband formation in $\mathrm{CuO}$ nanoparticles. The optical band structure and optical transitions are affected by the width of the localized states available in the band gap, which is called the Urbach tail. Therefore, the $\mathrm{CuO}$ nanoparticles can be used in semiconductor devices such as photoamplifier, photovoltaic cell, and photo detectors. 


\section{Conclusion}

The $\mathrm{CuO}$ nanoparticles were successfully prepared via sonochemical method. The crystallite size of $\mathrm{CuO}$ was found to be $21 \mathrm{~nm}$. Distribution of spherical $\mathrm{CuO}$ nanoparticles was observed from micrographical analysis. The average particle size was clearly visualized and measured $57 \mathrm{~nm}$, respectively, through TEM and PSA studies. Optical properties of $\mathrm{CuO}$ nanoparticles were analyzed/ clarified through UV absorption. The direct band gap of $\mathrm{CuO}$ nanoparticles was found to be large. Moreover, the absorption coefficient, optical conductivity, refractive index along with extinction coefficient and Urbach energy were calculated through UV absorption. The $\mathrm{CuO}$ nanoparticles could be used as an extensive semiconductor, optical devices, solar cell applications, and so on.

Open Access This article is distributed under the terms of the Creative Commons Attribution 4.0 International License (http:// creativecommons.org/licenses/by/4.0/), which permits unrestricted use, distribution, and reproduction in any medium, provided you give appropriate credit to the original author(s) and the source, provide a link to the Creative Commons license, and indicate if changes were made.

\section{References}

Almqvist N (1996) Fractal analysis of scanning probe microscopy images. Surf Sci 355:221-228

Chen LB, Lu N, Xu CM, Yu HC, Wang TH (2009) Electrochemical performance of polycrystalline $\mathrm{CuO}$ nanowires as anode material for Li ion batteries. Electrochim Acta 54:4198-4201

Chiang CY, Aroh K, Ehrman SH (2012) Copper oxide nanoparticle made by flame spray pyrolysis for photoelectrochemical water splitting-Part I. CuO nanoparticle preparation. Int J Hydro Ener 37:4871-4879

Cho S (2013) Optical and electrical properties of $\mathrm{CuO}$ thin films deposited at several growth temperatures by reactive $\mathrm{RF}$ magnetron sputtering. Met Mater Int 19:1327-1333

Essic J, Mather R (1993) Characterization of a bulk semiconductors band gap via near- absorption edge optical transmission experiment. Am J Phys 61:646-649

Gandhi S, Subramani RHH, Ramakrishnan T, Sivabalan A, Dhanalakshmi V, Nair MRG, Anbarasan R (2010) Ultrasound assisted one pot synthesis of nano-sized $\mathrm{CuO}$ and its nanocomposite with poly(vinyl alcohol). J Mater Sci 45:1688-1694

Greenwood R (2003) Review of the measurement of zeta potentials in concentrated aqueous suspensions using electroacoustics. Adv Colloid Interface Sci 106:55-81

Growth A (2011) structure and optical characterization of Al-doped $\mathrm{ZnO}$ nanoparticle thin films. Crys Res Tech 46:1086-1092

Hamad TK, Yusop RM, Al-Taay WA, Abdullah B, Yousif E (2014) Laser Induced Modification of the Optical Properties of NanoZnO Doped PVC Films. Int J Poly Sci 2014:787595-787603

Honsi HM, Fayek SA, El-Sayed SM, Roushdy M, Soliman MA (2006) Optical properties and DC electrical conductivity of Ge28-xSe72Sbx thin films. Vacuum 81:54-59

Huang CY, Chatterjee A, Liu SB, Wu SY, Cheng CL (2010) Photoluminescence studies on a single $\mathrm{CuO}$ nanowire. Appl Surf Sci 256:3688-3692
Kaur M, Muthe KP, Despande SK (2006) Growth and branching of $\mathrm{CuO}$ nanowires by thermal oxidation of copper. J Cryst Growth 289:670-675

Khalil SG, Ameen MA, Jubier NJ (2011) Effect of laser irradiation on the optical properties of $\mathrm{SnO} 2$ films deposited by post oxidation of metal films. Baghdad Sci J. 8:1-8

Kidowaki H, Oku T, Akiyama T, Suzuki A, Jeyadevan B, Cuya J (2012) Fabrication and characterization of CuO-based solar cells. J Mater Sci Res 1:138-143

Lang XY, Zheng WT, Jiang Q (2006) Size and interface effects on ferromagnetic and antiferromagnetic transition temperatures. Phys Rev B 73:224444-224450

Lim YF, Choi JJ, Hanrath T (2012) Facile Synthesis of Colloidal CuO Nanocrystals for Light-Harvesting Applications. J Nanomater 2012:393160-393166

Lin HH, Wang CY, Shih HC, Chen JM, Hsieh CT (2004) Characterizing well-ordered $\mathrm{CuO}$ nanofibrils synthesized through gas-solid reactions. J Appl Phys 95:5889

Lupi S, Ortolani M, Baldassarre L, Calvani P (2005) Optical conductivity and charge ordering in Nax CoO2. Phys Rev B 72:024550-024554

Madhup DK, Subedi DP, Chimouriy SP (2010) Optical characterization and thickness estimation of $\mathrm{Al} 3$ + ion doped $\mathrm{ZnO}$ nanofilms from transmittance spectra. J Optoelectron Adv Mat 12:1035-1044

Mahapatra O, Bhagat M, Gopalakrishnan C, Arunachalam KD (2008) Ultrafine dispersed $\mathrm{CuO}$ nanoparticles and their antibacterial activity. J Exp Nanosci 3:185-193

McAuleya CB, Dub Y, Wildgoosea GG, Comptona RG (2008) The use of copper(II) oxide nanorod bundles for the non-enzymatic voltammetric sensing of carbohydrates and hydrogen peroxide. Sen Actu B 135:230-235

Millis AJ, Zimmers A, Lobo RPSM, Bontemps N, Homes CC (2005) Mott physics and the optical conductivity of electron-doped cuprates. Phys Rev B 72:224517-224521

Mishra RL, Mishra SK (2009) Optical and gas sensing characteristics of tin oxide nano-crystalline thin film. J Ovonic Res 5:77-85

Morales J, Sanchez L, Martin F, Ramos-Barrado J, Sanchez M (2005) Use of low-temperature nanostructured $\mathrm{CuO}$ thin films deposited by spray-pyrolysis in lithium cells. Thin Solid Films 474:133-139

Moss TS, Burrell GJ, Ellis B (1973) Semiconductor opto-electronics. Butterworth \& Co Ltd., London

Muhibbullah M, Hakim MO, Choudhury MGM (2003) Studies on Seebeck effect in spray deposited $\mathrm{CuO}$ thin film on glass substrate. Thin Solid Films 423:103-110

Qi JQ, Tian HY, Li LT, Lai H, Chan W (2007) Fabrication of $\mathrm{CuO}$ nanoparticle interlinked microsphere cages by solution method. Nanoscale Res Lett 2:107-111

Radhakrishnan AA, Beena BB (2014) Structural and optical absorption analysis of $\mathrm{CuO}$ nanoparticles. Ind $\mathrm{J} \mathrm{Adv}$ Chem Sci 2:158-161

Son DI, You CH, Kim TW (2009) Structural, optical, and electronic properties of colloidal $\mathrm{CuO}$ nanoparticles formed by using a colloid-thermal synthesis process. Appl Surf Sci 255:8794-8797

Stewart SJ, Multigner M, Marco JF, Berry FJ, Hernando A, Gonzalez JM (2004) Thermal dependence of the magnetization of antiferromagnetic copper (II) oxide nanoparticles. Solid State Commun 130:247-251

Sumangala D, Amma D, Vaidyan VK, Manoj PK (2005) Structural, electrical and optical studies on chemically deposited tin oxide films from inorganic precursors. Mater Chem Phy 93:194-201

Tauc J, Grigorovici R, Vancu A (1966) Optical properties and electronic structure of amorphous germanium. Phys Status Solidi B 15:627-634 
Teng F, Yao W, Zheng Y, Yutao M, Teng Y, Xu T, Liang S, Zhu Y (2008) Synthesis of flower-like $\mathrm{CuO}$ nanostructures as a sensitive sensor for catalysis. Sen Actu B 134:761-768

Wang SQ, Zhang JY, Chen CH (2007) Dandelion-like hollow microspheres of $\mathrm{CuO}$ as anode material for lithium-ion batteries. Scr Mater 57:337-340
Xu Y, Chen D, Jiao X, Xue K (2007) CuO microflowers composed of nanosheets: synthesis, characterization and formation mechanism. Mater Res Bull 42:1723-1731

Xue SW, Zu XT, Zhou WT (2008) Effects of post-thermal annealing on the optical constants of $\mathrm{ZnO}$ thin film. J. Alloys Compds 448:21-26 